\title{
Ovarian Adenosarcoma
}

National Cancer Institute

\section{Source}

National Cancer Institute. Ovarian Adenosarcoma. NCI Thesaurus. Code C7317.

A biphasic neoplasm that arises from the ovary and is characterized by the presence of mullerian-type epithelial tissue in a mesenchymal sarcomatous stroma. The presence of a high grade sarcomatous component is associated with recurrences and metastases. 